\title{
Entre el desacato y la prudencia. Laicos católicos, jerarquía eclesiástica y gobierno revolucionario en el Aguascalientes de 1914.
}

LUCIANO RAMÍREZ HURTADO

Departamento de Historia/UAA

\section{RESUMEN}

Las medidas anticlericales impuestas por el gobierno constitucionalista en Aguascalientes entre julio y diciembre de 1914 provocaron diversas reacciones. La cautela y la prudencia ordenadas por la jerarquía eclesiástica contrastaron con el espíritu de iniciativa y el atrevimiento de algunos laicos y sacerdotes, que decidieron enfrentar por su cuenta las amenazas del gobierno revolucionario.

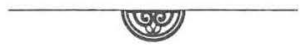

ABSTRACT

\section{BETWEEN THE IRREVERENCE AND THE PRUDENCE}

The anticlerical dispositions imposed by the constitucionalista government in Aguascalientes, between July and December in 1914, provoked several reactions. The caution and the prudence ordered by the eclesiastic hierarchy contrasted with the spirit of initiative and the daring laymen and priests, who decided to face on themselves the menaces of the revolutionary government.

${ }^{1}$ Ponencia presentada en el Segundo Encuentro Regional de Investigadores del Fenómeno Religioso del Centro Occidente de México, celebrado en la Universidad Autónoma de Aguascalientes el 18 y 19 de marzo de 1999. 
A nivel nacional, los dirigentes del Ejército Constitucionalista, a instancias de Venustiano Carranza, estaban convencidos de que la Iglesia Católica había contribuido al derrocamiento de Madero y había concertado una alianza con el régimen de Victoriano Huerta. De esa manera, "en el curso del verano de 1913 se concretó una resurrección de la oposición irreductible que había existido durante más de un siglo entre la Iglesia y el liberalismo mexicano. Este nuevo anticlericalismo tenía las mismas raíces que el de los siglos XVIII y XIX". ${ }^{2}$ La postura radical de los revolucionarios se vio exacerbada en sus sentimientos anticlericales gracias a dos sucesos, fundamentalmente:

El primero fue que durante el régimen de Huerta se realizó con su consentimiento un acto religioso llamado "Consagración Nacional de México al Sagrado Corazón de Jesús". El otro hecho fue que el Arzobispo de México, a solicitud de Victoriano Huerta, consiguió entre los ricos católicos 25 mil pesos que le prestó al usurpador. ${ }^{3}$

Por esos motivos los revolucionarios, en términos generales, cada vez que tuvieron oportunidad de castigar y hostilizar a la Iglesia Católica, lo hicieron sin contemplaciones. La prensa constitucionalista contribuyó de manera importante a tal propósito; el diario capitalino El Demócrata publicó una serie de artículos que trataban de documentar la complicidad de la alta jerarquía del clero mexicano con el ministro de Gobernación del régimen huertista. ${ }^{4} \mathrm{El}$ go-

2 Jean Meyer, La cristiada, volumen 2: El conflicto entre la Iglesia y el Estado, 1926-1929, México, 13a. ed., Siglo XXI Editores, 1994, pp. 66-67.

${ }^{3}$ Yolanda Padilla Rangel, El catolicismo social y el movimiento cristero en Aguascalientes, Aguascalientes, Instituto Cultural de Aguascalientes, 1992, p. 43. Véase para este mismo tema el trabajo de José Antonio Gutiérrez Gutiérrez, La labor social de la Iglesia católica en Aguascalientes, Aguascalientes, Instituto Cultural de Aguascalientes-Diócesis de Aguascalientes, 1997, pp. 168-169.

4 "Pruebas fehacientes de la unión entre los soldados traidores y los frailes reaccionarios", en El Demócrata, México, D. F., 10-X-1914. La nota señala que se encon-

132 C 
bierno revolucionario instaurado en Aguascalientes en la tercera semana de julio de 1914, impulsó y permitió una política anticlerical en el estado. En otras partes del país ya se habían venido ordenando medidas anticlericales, muchas de ellas ejecutadas con lujo de violencia. Por ejemplo, tanto en Nuevo León como en San Luis Potosí, entidades de donde procedían los nuevos mandatarios instaurados en Aguascalientes, las autoridades militares decretaron el arresto y expulsión de curas que no lograron comprobar su comple-

- ta abstención en asuntos políticos, particularmente si eran extranjeros; asimismo, impusieron ${ }^{5}$ préstamos forzosos y despojaron de bienes muebles e inmuebles a miembros de la alta jerarquía eclesiástica, además de prohibir la celebración de misas y el repique de campanas, so pena de arriesgarse a severos castigos. ${ }^{6}$

Una serie de acciones similares, de corte anticlerical, se realizaron en Aguascalientes, teniendo en ellas un papel preponderante las autoridades militares, el gobernador y el secretario de gobierno. Cierre de templos, quema de confesionarios, prohibición de repique de campanas, muestras de regocijo, así como hostigamiento, persecución, aprehensión y expulsión de sacerdotes, son algunas de dichas acciones concretas; además, se emprendió una intensa campaña anticlerical en el diario local La Evolución, lo mismo edi-

tró un archivo de Aureliano Urrutia, secretario de Gobernación de Huerta, en el que se halló un intercambio epistolar muy comprometedor entre dicho funcionario y algunos obispos, tales como Mora y del Río y Gillow.

${ }^{5}$ Rodrigo Mendirichaga, Los cuatro tiempos de un pueblo. Nuevo León en la Historia, Monterrey, 1985, p. 324.

${ }^{6}$ Medidas anticlericales en San Luis Potosí bajo el gobierno del general y comandante militar Eulalio Gutiérrez en Primo Feliciano Velazquez, Historia de San Luis Potosí, México, Ed. Cultura Sociedad Mexicana de Geografía y Estadística, vol. 4, pp. 230-232, 256-259. Disposiciones anticlericales en el estado de Nuevo León, véase Francisco Vela González, Diario de la Revolución, enero-octubre de 1914, tomo II, Monterrey, ed. Alfonso Reyes, 1983, pp. 388 y 389, así como el trabajo de Oscar Flores Torres, Burguesía, militares y movimiento obrero en Monterrey, Monterrey, Universidad Autónoma de Nuevo León-Facultad de Filosofía y Letras, 1981, p. 104. 
toriales que adhesiones, composiciones literarias que artículos. Una de las primeras declaraciones del gobernador Alberto Fuentes Dávila cuando tomó posesión de su cargo fue la siguiente:

El Gobierno de mi cargo jamás ha tenido la intención de atacar a la religión, sino únicamente perseguir a aquellas personas que en nombre de ella, abusan "de la ignorancia de los incautos, y violan la honra de los buenos ciudadanos.?

Desde su llegada a Aguascalientes el profesor y teniente coronel David Berlanga, quien fungió como secretario de gobierno y profesaba ideas socialistas, fue el principal promotor de medidas anticlericales. En su discurso del 26 de julio de 1914, en la plaza principal de Aguascalientes, Berlanga declaró a manera de reproche que inmediatamente después de que las autoridades huertistas abandonaron la ciudad y el estado, el pueblo de Aguascalientes debió, en su opinión, de haberse volcado a las calles, para

...torturar a los bandidos de sotana que han mantenido a las masas en la ignorancia para explotarlas, y debían de haber ido a cerrar los templos para transformarlos en escuelas, y ya que no lo hizo así, debe exigir al gobierno revolucionario que lo haga. ${ }^{8}$

El padre Felipe Morones, testigo presencial de algunos de los hechos a que nos vamos a referir, rememora que ante el inminente arribo de los revolucionarios a esta población, muchas personas comprometidas con el gobierno huertista, entre quienes se incluían algunos sacerdotes, salieron de la ciudad. ${ }^{9}$ Uno de los que salió con la suficiente anticipación, sabedor del encono con que venían actuando los revolucionarios, fue el obispo Valdespino y Díaz, que

\footnotetext{
${ }^{7}$ La Evolución, 23-VIII-1914.

${ }^{8}$ La Evolución, 23-VIII-1914.

' Felipe Morones, Capítulos sueltos o apuntes para la persecución religiosa en Aguascalientes, México, Imprenta Aldina, 1955, pp. 153-159.
} 
había tomado posesión de su cargo en mayo del año anterior..$^{10}$ Desde que era obispo de Sonora, en 1910, Valdespino había condenado y criticado a los rebeldes maderistas; más tarde, en 1913-14, ya como obispo de Aguascalientes, censuró "los tiempos calamitosos que atravesamos" y se lamentó por los peligros y "circunstancias aflictivas por que atraviesa nuestra casa patria", ${ }^{11}$ en clara alusión a la revolución constitucionalista. Se autodesterró a San Antonio, Texas, entre 1914 y 1917, tres años en que se vio obligado a separarse de Aguascalientes, huyendo "del huracán que nos devasta", ${ }^{12}$ en una "etapa de turbulencias y convulsiones sociales, políticas y religiosas" de la historia del país.

Sin embargo, algunos sacerdotes decidieron quedarse, aunque el miedo se apoderó de la mayoría, según confiesa el padre Morones. Por este motivo no se ofició misa en ningún templo de la ciudad el domingo 26 de julio de 1914. Otro síntoma del temor generalizado entre los sacerdotes es el hecho de que hubiesen decidido quitarse el hábito, vistiéndose de laicos. Refiere que hubo algunos que actuaron con suma prudencia al no portar el hábito públicamente, se vistieron de charro o de simples parroquianos. No deseaban llamar la atención ni arriesgarse a ser víctimas del odio que se tenía contra ellos. ${ }^{13}$

Las autoridades constitucionalistas habían dado la orden de cerrar los templos tanto en la capital como en el resto del estado. La reacción contraria no se hizo esperar. El pueblo de Aguascalientes, mayoritariamente católico, se irritó. El 11 de agosto hubo una ma-

${ }^{10}$ Archivo de la Mitra del Obispado de Aguascalientes, Libro de Gobierno No. 14, f. 88 vta. y 89 fte. (en adelante citado AMOA).

${ }^{11}$ AMOA, $L G$, caja No. 3, Libro 14 (3), fs. 3 vta. y 6 fte. y fs. 104 vta. y 105 fte.

${ }^{12}$ AMOA, $G$, exp. Excmo. Sr. Obispo Ignacio Valdespino. Valdespino regresó a Aguascalientes a finales de 1918 pero tuvo que salir nuevamente al exilio cuando la guerra cristera, muriendo el 12 de mayo de 1928 en San Antonio, Tex.

${ }^{13}$ F. Morones, Op. cit., p. 155. 
nifestación de mujeres, principalmente profesoras, protestando contra el gobierno por el cierre de los templos; se quejaron ante el general Pánfilo Natera, le solicitaron las llaves de los mismos, a lo que el general zacatecano contestó categórico que no podía ni quería obstaculizar las disposiciones de las autoridades revolucionarias.

La tribuna desde donde se lanzaron los ataques más persistentes contra la Iglesia, fue el periódico constitucionalista La Evolución, bajo la dirección de Berlanga. La manifestación de los laicos católicos provocó a su vez una reacción anticlerical. Llegaron al diario varias cartas de apoyo, incitando a las autoridades a no permitir ese tipo de protestas; se pedía acabar con los sacerdotes y terminar de una vez por todas con la propagación de la ignorancia fomentada por el clero. El 13 de agosto, Rafael Castillo Pacheco, viejo periodista anticlerical, publicó un artículo titulado "Acerca de la cuestión religiosa", en el que se señalaba que el clero no había sabido cumplir con su deber de moralizar al pueblo, traicionando, por el contrario, las ideas de progreso y civilización. Desde La Evolución se atacaba el bautismo, la confesión auricular, se regocijaban ante la muerte del Papa Pío X y se publicaban composiciones literarias de tinte materialista y artículos marcadamente ateos. ${ }^{14}$

Ante la presión pública, el gobernador Fuentes Dávila concedió la apertura de cuatro templos ubicados tanto en el centro histórico como en algunos barrios tradicionales de la ciudad de Aguascalientes: Catedral Basílica, El Encino, Guadalupe y La Purísima, a cambio de que fueran los propios sacerdotes quienes, dentro de los templos, hicieran propaganda en contra de la confesión. Al jefe político de la capital se le ordenó vigilara la estricta observancia de esta disposición. ${ }^{15}$ Únicamente se permitiría oficiar misas en los templos y después permanecerían cerrados; quedó prohibido brindar otro tipo de servi-

\footnotetext{
${ }^{14}$ La Evolución, 3, 5, 6, 8, 11, 13, 15, 16, 21, 27-vill-1914; 4 y 5-IX-1914.

${ }^{15}$ Archivo General Municipal de Aguascalientes, fondo histórico, caja 406, exp. 3, caja 410, exp. 6. (en adelante citado AGMA, $H$ ).
} 
cios eclesiásticos. La reacción de la población católica fue inmediata y se organizaron en comisiones para solicitar ante las autoridades militares la reapertura de los demás templos y la normalización del culto. Algún sacerdote y un grupo de señoras se tomaron el atrevimiento de tramitar la solicitud sin "el expreso acuerdo" y la "debida autorización" de la superioridad eclesiástica, cosa que molestó a las autoridades civiles y enseguida vino el amago de castigo. Por ello se mandó una circular a todos los sacerdotes de la diócesis, según la cual, en virtud "de las difíciles circunstancias por que atravesamos, y que por propia experiencia nos constan los gravísimos peligros en que nos ha colocado, no una sino varias veces, la injerencia de ciertas personas que sin la debida autorización y con no poca imprudencia, han tomado en asuntos de seria importancia cerca del Gobierno civil", se prohibía terminantemente tomaran cualquier iniciativa, sea del clero regular, secular o laico, para acercarse a las autoridades civiles sin autorización. ${ }^{16}$

El gobierno civil prohibió también, de manera verbal pero terminante, el repique de campanas sin su consentimiento. Por ello, el señor J. de Jesús López y González, provicario encargado del gobierno eclesiástico en ausencia del autodesterrado obispo Valdespino -futuro tercer obispo de Aguascalientes- emitió una circular a los párrocos, comunicándoles la orden del gobierno en el sentido de que se acatase dicha orden, en virtud de lo delicado y comprometido de la situación, a pesar de que Aguascalientes era una ciudad eminentemente católica cuya población estaba acostumbrada a escuchar los tres toques del Angelus y el De Profundis, pues el sonido de las campanas ayudaba, decían las autoridades eclesiásticas, a despertar "el espíritu religioso y a marcar de una manera característica el estado del corazón de los fieles" ${ }^{97}$ La circular decía:

\footnotetext{
${ }^{16}$ AMOA, LG, caja 3, Libro de Gobierno No. 14 (3), fs. 14 vta. a 15 vta.

${ }^{17}$ AMOA, LG, caja 3, Libro No. 14. (3), fs. 7 fte. a 9 fte.
} 
Con íntima pena de nuestro corazón dictamos las anteriores medidas, en apariencia de acuerdo con la injusta guerra de que ha sido víctima la inocente Iglesia; pero resueltos a seguir un camino de recta conciliación y cristiana providencia, indispensable en la época presente, estamos convencidos por propia y dolorosa experiencia, que nada es más práctico para remediar paulatinamente los enormes males que sufrimos. ${ }^{18}$

Hubo un intento frustrado de rebelión contra el gobierno constitucionalista. El cura de Jalpa, Juan Ibarra, se levantó en armas con cuatrocientos hombres y el 24 de agosto de 1914 una columna del ejército revolucionario salió a combatirlo a la hacienda de La Luz, Zac., a seis leguas de la villa de Calvillo, "pues parece que abriga la intención de tomar aquella"19 plaza. El gobierno constitucionalista dictó orden de aprehensión contra "algunos portadores de la pestilente sotana", entre ellos el párroco de Calvillo, que estaban en connivencia con el cura de referencia.

Fuera de este incidente, la respuesta de la Iglesia Católica ante los acontecimientos fue el silencio. Hubo, sin embargo, una resistencia altamente riesgosa que demandaba suma cautela, si no querían exponerse a las persecuciones y represalias por parte de las autoridades militares.

Reconoce el padre Morones que algunos sacerdotes, a pesar de la prohibición se arriesgaban a desobedecer las órdenes dispuestas. Por otro lado, menciona que la propia tropa solicitaba de los curas servicios tales como bendición de imágenes y celebración de casamientos. ${ }^{20}$ En el primer semestre de 1914 hubo 127 solicitudes de matrimonio eclesiástico, mientras que para la segunda parte del año hubo 99 solicitudes matrimoniales, lo que equivale a una disminución de tan sólo el $22.1 \%$ respecto al semestre anterior ${ }^{21}$. Ello

\footnotetext{
${ }^{18}$ AMOA, $L G$, caja 3, Libro de Gobierno 14 (3), fs. 14 fte. y vta.

${ }^{19}$ La Evolución, 25-VIII-1914.

${ }^{20}$ F. Morones, Op. cit., pp. 153-159.

${ }^{21}$ АмОА, IM, саја 93, 1913-1917.
} 
significó un nuevo desacato a las disposiciones gubernamentales, dado que se habían dado órdenes expresas de no prestar este tipo de celebraciones religiosas.

Otra medida iconoclasta de parte de las autoridades militares que causó gran expectación entre la población aguascalentense fue la quema pública de confesionarios a la puerta de los edificios católicos, así como la profanación de imágenes. El 26 de julio el secretario de gobierno lanzó una arenga que llevó al terreno de la práctica un mes después:

es preciso ahora para cumplir con nuestro deber como revolucionarios... destruir al clero, quemarle todos los medios que ha tenido para sembrar la superstición y fomentar el fanatismo. ${ }^{22}$

El 25 de agosto de 1914 el diario La Evolución anunció que, "a solicitud de algunas señoritas de la localidad, hoy serán quemados los confesionarios y algunos otros ornamentos de los frailes en la Plaza de Guadalupe". ${ }^{23}$ Se dijo que sería un acto en pro de la civilización y del mejoramiento intelectual y moral del pueblo. Se invitó a todas las familias para que llevasen a sus hijos a presenciar el "acto solemne" donde se les explicaría la importancia y significación del evento. Se sustrajeron los confesionarios e imágenes religiosas de distintos templos, mismos que fueron acumulados en el lugar acordado y se les prendió fuego; y "cuando la hoguera estaba en toda su fuerza, la Srita. Emma Rodríguez tomó la palabra, explicando a la multitud que presenciaba el acto, lo necesario que era la desaparición inmediata del confesionario, que por tanto tiempo sirvió al clero para mantener la ignorancia en nuestro país, desarrollando el fanatismo en la sociedad". ${ }^{24}$ La prensa constitucionalista afirmó que la señorita profesora fue muy aplaudida por "el pue-

\footnotetext{
${ }^{22}$ La Evolución, 27-VIII-1914.

${ }^{23}$ Ibid. 25-VIII-1914.

${ }^{24}$ Ibid. 26-VIII-1914.
} 
blo", que en "compacta muchedumbre" concurrió a la incineración de los confesionarios. No pudo faltar al acto, por supuesto, el profesor revolucionario:

El Teniente Coronel David G. Berlanga, que también asistió a presenciar la incineración, tomó la palabra felicitando al pueblo por aquel acto que había pedido y que con justicia le fue concedido, diciéndole que podían volver tranquilos a sus hogares; pues que los frailes no oirían más los lamentos de sus esposas e hijas, ni sembrarían la ignorancia por más tiempo en el pueblo, pues que éste había deshecho para siempre en esos momentos a uno de los enemigos más grandes que se oponían a su adelanto y felicidad. ${ }^{25}$

Además, con el pretexto de mejorar las condiciones materiales en el ramo de la instrucción pública, "y para ver de lograr locales... higiénicos y suficientemente amplios, se ha ordenado la desocupación de todos los conventos para convertirlos en escuelas" ${ }^{26}$ Es por ello que "el edificio de magnífica construcción que el clero destinaba al Seminario, se destinará para Escuela Normal...". ${ }^{27}$ Efectivamente, el gobierno revolucionario intervino el colegio católico, hizo algunas reformas y determinó que ahí se estableciera la sede de la Escuela Normal para Profesores (únicamente varones), establecimiento que fue inaugurado el 1 de diciembre de $1914 .{ }^{28}$

El clero católico debió escandalizarse ante tales demostraciones, pero atemorizados por la presencia amenazante de las autoridades militares, prefirieron guardar un prudente silencio.

$\mathrm{El}$ actual cronista de la ciudad de Aguascalientes refiere que por esta época el gobernador y comandante militar del estado, junto con su secretario de gobierno intentaron apoderarse del templo de San Antonio, construido por el arquitecto autodidacta Refugio Reyes en 1907 y que permanecía cerrado por orden expresa del go-

\footnotetext{
${ }^{25}$ Ibidem.

${ }^{26}$ El Liberal, 12-X-1914.

${ }^{27}$ Ibidem.

${ }^{28}$ AGMA, H, caja 402, exp. 11.
} 
bierno, con la intención de convertirlo en Palacio Legislativo. Esto ocurrió en octubre, cuando ya estaba la Soberana Convención Revolucionaria. Sin embargo, un aguerrido contingente de personas, en el que abundaban mujeres que laboraban en los puestos del mercado Terán, encabezadas por la señora Adela Douglas -hija del rico empresario de origen escocés John Douglas y que "no le tenía miedo ni al diablo"-29, al saber tal propósito, se adueñaron del templo y atrincheradas repelían a pedradas a quien osase acercarse, particularmente si era alguien del gobierno. Surgió un estribillo popular:

\author{
Entre Fuentes Dávila y Berlanga, \\ quisieron tomar San Antonio, \\ pero se les hizo fiebre, \\ a los jijos de un demonio. ${ }^{30}$
}

La reapertura de los demás templos al culto público se realizó hasta que el gobierno de la Convención y Alberto Fuentes Dávila habían abandonaron el estado. Se instaló un gobernador villista en Aguascalientes y el propio Centauro del Norte entregó las llaves de los templos de San José, San Marcos, La Merced, La Enseñanza, Nuestra Señora de la Salud y San Juan Nepomuceno en manos del padre Morones, no sin antes decretar la expulsión de los sacerdotes extranjeros del territorio de Aguascalientes. ${ }^{31}$

Los siguientes años en Aguascalientes fueron de una convivencia difícil, enmedio de un clima tenso. Los gobernadores carrancistas en la entidad, si bien quisieron meter en cintura a la Iglesia mediante ciertas prohibiciones y amenazas, permitieron la reorganización de los católicos (celebración de conferencias morales, proliferación de

${ }^{29}$ F. Morones, Op. cit., p. 156.

${ }^{30}$ Entrevista con el Profr. Alejandro Topete del Valle, cronista de la ciudad de Aguascalientes, marzo de 1989.

${ }^{31}$ AMOA, $L G$, Libro de Gobierno No. 14, fs. 121 fte. y 122 vta. Cfr. F. Morones, $O p$. cit., p. 159. 
asociaciones de laicos, escuelas de ambos sexos a su cargo) así como la reanudación completa del culto (aplicación de sacramentos, celebración de misas, etc). ${ }^{32}$

Todavía en septiembre de 1918, en clara alusión al artículo 130 constitucional, los consultores de la Mitra del obispado de Aguascalientes, reunidos en la sala episcopal, se preguntaban cual sería la conducta del gobierno eclesiástico diocesano en caso de que el gobierno civil quisiera reglamentar el culto católico en el estado, tal como había sucedido ya en otras partes de la República, llegando a la resolución de que rechazarían categóricamente todo intento de injerencia del gobierno civil respecto a la disciplina de la Iglesia

puesto que de ninguna manera la Iglesia depende del Estado, ni éste débe legislar en ella. Más en la práctica, debe aprovecharse la más insignificante libertad que se deje para ejercer el santo ministerio, y cumplir con este sagrado deber, atendiendo a la salud de las almas, que de ninguna manera se han de abandonar mientras se tenga un rasgo de tolerancia para ejercer. ${ }^{33}$

A pesar de todas las adversidades del período constitucionalista, "el culto y la piedad religiosa" ${ }^{34}$ no decayeron en Aguascalientes, un estado abrumadoramente católico. A ello contribuyeron la prudencia de las autoridades eclesiásticas y la activa militancia de los laicos, que a título personal o a nombre de alguna asociación se atrevieron a desobedecer abiertamente las disposiciones anticlericales del gobierno. Una década más tarde, cuando el conflicto religioso y la guerra cristera se hicieron presentes, cambiarían el escenario y las circunstancias, no así sus actores.

\footnotetext{
${ }^{32}$ AMOA, LC, libro 14, fs. 18 vta.-19 fte.; 23 fte. y vta.; 24 fte. y vta.; 123 fte. y vta.; 130 fte. y vta.

${ }^{33}$ AM0A, caja "Sec. de Gobierno, Diócesis, datos históricos, 1899-1976"

${ }^{34}$ José Antonio Gutiérrez Gutiérrez, Op. cit., p. 171.
} 